\title{
On the Father Images by Anderson and Faulkner - Illustrated by the Triumph of the Egg and Barn Burning
}

\author{
Qian Bai and Yu Sun
}

\begin{abstract}
The works of Sherwood Anderson and William Faulkner have aroused the extensive attention of the critics in the world. The conventional study puts its focus on the respective contents of the two writers' novels. Enough attention is not paid on the comparative study on the father images between Anderson and Faulkner, Their works both contain profound historical connotations, yet the connection between the novel and New Historicism has remained for the most part unexplored. Consequently, based on the previous studies, the present paper, with the method of close reading, attempts to proclaim the effect to the two father images under the imbalanced value in social transition. Meanwhile, the paper also tries to reinterpret Anderson and Faulkner's historical consciousness in The Triumph of the Egg and Barn Burning from the perspective of New Historicism, particularly applying the concept of "the Historicity of text", which could add a better understanding to the text and history relationship in the two stories. At last, the paper reflects New Historicism is feasible for text interpretation and sheds enlightenment on the future studies of the application of New Historicism.
\end{abstract}

Index Terms-The father image, Sherwood anderson, william Faulkner, new historicism.

\section{INTRODUCTION}

Sherwood Anderson, a novelist in the early 20th century, has a great effect on later generations in American Literature, such as Hemingway, Faulkner, and Steinbeck. Interviewed by The Paris Review in 1956, Faulkner said that Anderson deserves the father of American literature in the period [1]. And Winesburg, Ohio published in 1919 lays the foundation for his status in literature and The Triumph of the Egg and Other Stories is considered to be one of his best works. It is the exquisite descriptions to the people who lose their spirits in the way of pursuing material living that makes Anderson win the first literature prize of The Dial in 1921 [2]. The father image in The Triumph of the Egg is a role of alienation in the society. If we go closely in the heart of Anderson, we can get the reason why he depicts such a character in his story.

Barn Burning is one of the classics by William Faulkner, nominated as the best American short novel, receiving the $\mathrm{O}$. Henry Awards in 1939 [3]. It paints the life of a southern white family after the civil war. The story expands through the eyes of a child of ten years old, facing the conflict between the justice and family reputation. Abner-the father is

Manuscript received May 2, 2017; revised July 23, 2017.

Qian Bai and $\mathrm{Yu}$ Sun are with School of Foreign Languages, Northwestern Polytechnical University, Xi'an 710072, PR China (corresponding author is Yu Sun, e-mail 1350823356@qq.com, sunyu@nwpu.edu.cn). bad-tempered, and he is used to deal with disputes with others by violence. When he and neighbor Harris are at odds, he burned the barn of Harris, which get him charged in the court. The youngest son of Abner had to forswear because he does not want to put his father into jail. Whereas, in the deep heart of the child, he is ambivalent since he know it is illegal. The previous studies mostly focus on the growth of the son, and the father Abner is also an important role for us to deeply understand this work.

Emerging, developing, and booming in the 1980s, New Historicism is a mode of literary study based on the parallel reading of literary and non-literary texts, usually of the same historical period. New Historicism attends primarily to the historical and cultural conditions which produced a text, as well as the meanings, effects and later critical interpretation and evaluation of the text [4]. Montrose once comments, "By the historicity of the texts, I mean to suggest the cultural specificity, the social embedment, of all modes of writing - also the texts in which we study them" [4]. The historicity of text offers a new perspective to the relation between text and history: history is not just the background information for text and affects the creation of text; on the other hand, text is created in a certain historical context, and it has the power to shape and change history. Anderson and Faulkner reconstructs the America provincial society accompanied the beginning of industrialization and the ending of civil war respectively. They successfully interweave social change with the local people's daily life, illustrated by the two typical characters of father.

Through the comparison of the two father images, the part II would show us the differences and similarities of the characters and their different life situations at first impression. Then the part III would focuses on "the historicity of text", which demonstrates Anderson and Faulkner's historical consciousness in certain society. The production of the text is the two writer's negotiation with the contemporary society. Both Anderson and Faulkner's personal experiences and the social background contribute to the creation of the text, which also hold historical importance.

\section{THE Two FATHER IMAgES}

Portraits, language, movements and psychology are the major methods applied to the description of characters. Sherwood Anderson and William Faulkner outstandingly present two seemingly different father images in their short stories by these accesses, especially the movements, words and psychological activities of the fathers. In Triumph of the Egg, Anderson employs much description of the father's 
behavior and psychological activities, thus presenting a whimsical father with his "inborn cheerfulness" [2]. However, by attaching great importance to the father's language, Faulkner gives readers an image of a man full of ferocity, tyranny, stubbornness as well as confidence, calmness and perseverance in his Barn Burning. The two fathers at first sight may seem totally different. But their similarities can also be found if related to their respective social backgrounds. These two opposite roles that have similarly lamentable life experience are analyzed as follows.

\section{A. The Appearances of the Two Fathers}

At the beginning of the story, the father was "intended by nature to be a cheerful, kindly man", working as a farm hand, gathering at Saturday nights, and living a satisfactory life as a bachelor. He does not take up an important job but a farm hand. He does not own plenty of property but a horse. And he does not have many hobbies except drinking some beer with his friends. The precise and vivid description to the father shows us a typically common man.

When the family move towards the town named Bidwell, we know "He was then a bald-headed man of forty-five, a little fat...there were two little patches of hair on father's head just above his ears" as in the story. It also takes him for nothing out of ordinary. The son considers the hair above father's ear as forests and he has ever dreamed of walking through the forests and finds a "far beautiful place where there were no chicken farms and where life was happy eggless affair". It indicates the hate of the son to chicken and eggs from his fantasy to his father's hair.

The identity of the father in Barn Burning is a poor white man and a sharecropper. The outside image of him manifests his strong character. In the novel, the father has a black and seemingly metallic coat. Those descriptions such as "stiff black coat", "the wiry figure", "a shape black, flat, and a bloodless as though cut from tin" give reader a sense of coldness and gloominess. The images of "black", "cold', "iron" symbolize his cruelness and fierceness. The image of father has been dehumanized for some certain reasons that would be told later.

The father in Barn Burning is lame, which is a significant symbol as well. James Ferguson thinks that limp makes the image weird; embodies his defiance and unsuitability to the reality [5]. The feature of limp also hints his identity as a sharecropper. The relationship between him and the land is not harmonious, further leading us to think about the gain sharing system in the south. The sharecroppers always get a little amount of income from southern planters.

In the novel, when the father come to see the new employer with his son, a black old man wearing "neat grizzled hair, in a linen jacket" stood in the doorway and replied "wipe your shoes, white man, fo you come in here" [3]. However, the father pushed the black man down and spoke to him "get out of my way, nigger", and then walked into the house directly [3]. The racial relationship presented here afford for thought that racism in the south not only exist in the black and the white as well as in the poor whites and landlords. Here The family of Abner is a representation of the poor whites. Abner regards him a more noble man than the black slave and the black man working in the farm looks down upon the poor whites. Their conflict symbolizes the sin of racism.

The appearances of the two fathers are totally different that one is nobody while the other is a hard-hearted man. It is said by Rodin that the external features of a man usually expose his inner spirit [6].

\section{B. The Father Image in the Triumph of the Egg}

The father in The Triumph of the Egg is gentle and cares much for his family. At the beginning, Sherwood Anderson demonstrates a whimsical man who has been gradually changed to be ambitious and unrealistic by both his wife and the society. At the beginning of the story, the father was "intended by nature to be a cheerful, kindly man", working as a farm-hand, gathering at Saturday nights, and living a satisfactory life as a bachelor. However, things began to change when father got married at the age of 35 and gave birth to "me". "They became ambitious. The American passion for getting up in the world took possession of them", as it said in the story [2]. It seems that mother and "I" should be responsible for the change, because mother has been deeply influenced by the books she has read in which several great Americans who "rose from poverty to fame and greatness", and she dreams about that too. And "I" am the motivation for father's ambition since all what he has done was intended to provide me with a brighter future. The father is a husband who listens to the advice of his educated wife and a responsible father. However, nothing could help him and he eventually failed.

As an average man being easily satisfied, some characteristics of the father in the story intensify his tragic destiny.

First, the father is a sufferer with a negative attitude and speculative notion. Optimism is one of essential qualities on the way of success for the inevitable setbacks. As mentioned in the story, the people like Garfield and Lincoln have not been defeated but taking an optimistic view of things. When the first struggle of raising chicken come to nothing, father become habitually silent and discouraged. The negative emotion might go against success and also provokes his psychology of speculative behavior. Facing increasing death of chickens due to the spread of the fowl plague in the farm, the father is crazy about the grotesque chickens instead of seeking a treatment to save his farm.

In the novel, "a chicken born that has for legs, two pair of wings, two heads or what not... the things do not live", "he had sort of notion that if he could but bring into henhood or roosterhood a five-legged hen or a two-headed rooster his fortune would be made", that kind of absurd idea occurs to the father [2]. He dreamed of taking the wonder to country fairs and getting rich by exhibiting it to other farm hands. The failure of chicken raising stimulates the growth of the abnormal psychology come into being. And he cannot deal with pressure and frustration properly, which turns him a crooked man.

$\mathrm{He}$ is also a victim of parochialism. Now that the father has become ambitious, he has to do something for his goal, so he transferred his business from chicken raising to restaurant management under the persuasion of his wife. And he tried to fight against the fate, which shows his unbending 
characteristic and the eager for success. The father gradually became whimsical and insane in the process of running the restaurant. He dreamt of displaying the "grotesques"- the strange chickens to entertain his customers, but failed and was laughed at, which made him breakdown in the end. Should he wake up to the realization, he could have improved his businesses of the farm and the restaurant.

From the farm hand, the owner of a chicken farm to the restaurant owner at last, the personality of being easily-satisfied, negative, narrow and opportunistic have never changed and the personality weaknesses have proved to be the obstacles to his American dream. Usually, we attribute the failure of an average man to the social matters, while the inner reasons of the character cannot be avoided.

\section{The Father Image in Barn Burning}

Compared to the changes the first father underwent, the father Abner in Faulkner's Barn Burning seems to be more stable and clinging. He is always so confident, strong-minded and imperturbable, but has confidence, calmness, and perseverance as well which are obviously reflected from his words and behavior in the story.

He was not a responsible and caring father to his sons and family. For instance, when Abner spoke for the first time during his trial, his voice was "cold and harsh, level, without emphasis", which showed that he was quite ruthless [3]. It is not common that a "crime" still hold such an unyielding and indifferent attitude when it comes to his sentence. Then later, when he was ready to move out of the country, he recalled the time when he had stolen a horse 30 years ago, "The wiry figure walking a little stiffly from where a Confederate provost's man's musket ball had taken him in the heel on a stolen horse thirty years ago, followed the two backs now" [3] He was a liar, a thief, and nobody would trust him or give any sympathy to him.

Abner is a man of tyrannical and fierce characteristics. While they were going out of the store, his younger child fought to against others for the defense of their reputation. However, the father just used his hand to "jerked him back" and his harsh, cold voice speaking above him: "Go and get in the wagon." Even when the mother wanted to descend the wagon and look for their son, he only said "get back" and "Get back in the wagon" [3]. We cannot imagine how a father should be so arbitrary and indifferent to his beloved ones. Perhaps it was because of his inborn personalities, or he had been upset by previous unpleasant experiences. Anyway, this kind of characteristic brought him much trouble in the rest part of the story.

It is also shown when the father took the younger son and educated him, "You are getting to be a man. You got to learn. You got to learn to stick to your own blood or you ain't going to have any blood to stick to you" [3]. The father was so concerned of their "blood", their root and dignity. He was used to command others, and acted as if he was a dominator, as in the story "Answer me!", "get on to bed. We will be there tomorrow", "Nevertheless, fit it will and you'll hog it and like it" [3]. All these he said revealed a sense of despotism.

He had so much confidence in himself that he could not trust anyone. "Don't you know all they wanted was a chance to get at me because they knew I had them beat?"[3] Abner thought that he could get through any difficulties by his own effort, but actually he could not. He was insistent to his heart, but too fierce. He would never change a little bit and the hatred of the owners of the manors was so great that it even cost his family and his life.

\section{THE CONNECTION BETWEEN THE FATHER IMAGES AND THE HISTORY}

Literature is intimately linked with other forms of representation and culture for historicist critics. It is also intimately linked with social background. According to "the Historicity of Text", all kinds of texts are the products of a certain history. They have a specific historicity [7]. They are influenced by history, culture, society, politics, institution and class. As a result, much attention should be paid to particular social background of the text when we interpret the text. The father images in the paper can be related to the certain social background when the authors create the writings.

\section{A. The Father in The Triumph of the Egg and Sherwood Anderson}

Living the transition from the old to the new century, Anderson witnesses the fast development of industrial civilization. During the period, the rich are getting richer, and the poor are getting poorer, when the traditional value falls apart along with the end of World War I and the fast development of industrialization. The residents farming for a living in country cannot adapt to the commercial age in a short time. Anderson always misses the old time and feels uneasy and disappointed to the new social circumstance [8]. The image of father in The Triumph of the Egg clearly conveys his distinct attitudes to the old and the new time. The father enjoyed his life when he was a farm hand while he became a miserable middle-aged adult when he moved in the big city and began doing business. The reason why Anderson creates such a role is that he regards the insane industrialization and utilitarianism as the root of all evil [9]. Anderson believes that one can be austere if he has no selfish desires so he tries to express his nostalgic feeling through the writings, in which he pays attention on the change of time and the panic of common people who lose the traditional value [9]. Sherwood himself is a writer who has been a businessman, which can help us to comprehend the anti-business sentiment and the lingering sense of alienation on himself.

Anderson demonstrates the alienation of common people in modern society in The Triumph of The Egg. The image of father in the story pointedly criticizes industrialization and commercialism while Anderson does not show a way out to the people. Marcus Cunliffe says that his generation (Anderson's) like to question despite the answer [10]. Taking Anderson's experience from a businessman to a writer, it is possible for individuals to struggle against alienation and change the way of life, which is, following his human nature but restraining unrealistic desire.

\section{B. Abner in Barn Burning and William Faulkner}

Faulkner spends most of his life in the southern town that is the source of creation. The regional culture of south affects greatly on his writing. Like other areas in America, the 
southern culture which consists of different matters is based on the Puritanism with the core of Calvinism. As an effective religious sect from the Religious Reformation in Europe in 16th century, Calvinism emphasizes the direct connection between human and God while it also believes in the doctrine of original sin and the decided fate, which suppresses the desire of human [11].

Besides, Puritanism asserts the absolute authority of men and claims that women and children should submit to the head of the family like what they deal with God. That's why in Puritan families, fathers are always tyrannical and fierce to rule their family members. Parts of the southern United States are referred to as the Bible Belt because fundamentalist Christians with strong beliefs have a lot of influence there [11]. As southern states are the Bible Belt dominated by the Puritanism, it is not hard for us to understand the cold-blooded and stubborn image of the father presented in Barn Burning. It's the patriarchy founded by Puritanism in South that makes the production of such an image of father.

By exposing tyrannical behavior and words of the father image in Barn Burning, Faulkner probes deeply and thoroughly into the causes for the disintegration of the old south. The loss of humanity and the moral decline not only exacerbate the contractions within the family but also accelerate the pace of the disintegration of the American South [12]. The father image, being brave, determined, indomitable but also stubborn, cold and selfish, can be regarded as the embodiment of the old south to some extent, which is the theme that Faulkner would like to express.

Faulkner is overwhelmed by mixed love-hate feelings to the southern society and traditional culture. On the one hand, he treasures the value of southern states with a deep and nearly irrational affection and misses the good quality of perseverance. On the other hand, he clearly witnesses the problems in southern areas such as the vicious nature and lethality of the father image in traditional south culture.

\section{The Comparison with the Two Images of Father}

Ander and Faulkner both choose to portray the life of common people and also express the alienation and disappointment to the miserable experience. At first sight, the two fathers may seem totally different from each other; one is gentle, cheerful, and caring for his family, while another is fierce, indifferent, tyrannical and rude to his families. However, if we think deeply and associate them with their social backgrounds, we can see that they do have some similarities.

Mainly there are two: one is that they are to some degree "over-confident" and have some kind of features of "male chauvinism"; and the other is that they are both the tragedies of the society. Looking back to the stories, there are many sentences in which it is easy to see that they are ambitious and confident. The father in The Triumph of the Egg is very obvious of that because he is always trying to succeed and wants to provide a better life for his family. He has never changed his idea of the strange chicken he cherished. But they are not the secret of success and at last he failed due to his stubbornness. And the father in Barn Burning is so tyrannical and has a very typical feature of chauvinism. We can easily see this from what he says and does. He has a fierce characteristic and never changes, and he will do whatever he determines to do.

There is no doubt that they are all tragic characters, but what causes their tragedies? Here comes another similarity, which is that they are all the victims of the society. By reading The Triumph of the Egg, we know that the story is set in a period of social transformation, during which period the "American Dream" is changing people's attitude towards life and "Westward Movement" makes money more important in people's life. So the father and his wife were influenced too. And Abner, it is certain that he was forced by the miserable life of the poor and the cruelness of the owners of the manors. They are all the reductions of the conflicts in society.

The Triumph of the Egg and Barn Burning present to us two different images of father who are both tragic and destroyed by the society. Although they have seemingly contradict characteristics: gentleness and ferocity, both of them suffer the mental crisis respectively in modern society and the end of the old south which are in great historic change. By reading these two stories, we cannot only sense the miserable life of poor people but also appreciate the writing techniques of Sherwood Anderson and William Faulkner. We know that we do need dignity and self-reliance, but should also be realistic and forbearing. These are not only suitable for the society the authors live, but can also be adapted to our current society, and we can indeed benefit from such kind of view for lifelong.

\section{CONCLUSION}

As the appearance of a specific history as well as culture, text is not only the representation and imitation. It also shows the writer's view on the historical events. Literature is the representation of culture, being similar to the phenomena happened in the past. In the same time, text affects the culture, too. All the texts can be considered as dynamic power in the development of history. They are an essential and significant part of history. In brief, all happenings are formed by the certain culture where they come out. In turn the events influence the culture.

History is far away from the objective and it is a pile of materials. Writers can pick several fragments to rearrange them for moral, education, and even political use. The literary writers are capable of composing these fragments of materials and making them more real and truthful than what really happened.

Different people could have distinct explaining to past due to the interference of their subjective consciousness. The descriptions of common people's daily life help Anderson and Faulkner to reconstruct their own interpretation of history and reflect contemporary history. This paper manages to conclude that The Triumph of both the Egg and Barn Burning are a production based on "the historicity of text." Anderson and Faulkner deliver us a powerful epic of the reconstruction of American society at different periods according their understanding. What's more, Anderson and Faulkner expose their persistence concern with universal humanity through the depictions towards the marginalized histories of the ordinary and common people. 


\section{REFERENCES}

[1] G. Plimpton, "The art of fiction No.12 William Faulkner," The Paris Review, vol. 12, 1956.

[2] S. Anderson, "The triumph of the egg and other stories," T. Jie. Ed. Selected Readings in American Literature, Beijing: Higher Education Press, 2000.

[3] W. Faulkne, Collected Stories of William Faulkner, New York: Vintage Books, 1987.

[4] M. Guo, "The interaction between texts and history-A new historicist reading of Light in August," M.S. thesis, Dept. English Teaching. Eng., Guizhou Normal Univ., Guizhou, China, 2014.

[5] Y. Li, "An intepretation to the father image in Barn Burning," Masterpieces Review, vol. 9, pp. 81-82, Sept. 2013.

[6] L. Goldscheider. Rodin. New York: Phaidon Press, 1996.

[7] T. Lois. New Historicism in Selective Reading in $20^{\text {th }}$ Century Western Critical Theory. Z. Zhang. Ed. Beijing: Foreign Language Teaching and Research Press, 2002.

[8] J. Yang., "The inevitability of small Patotoes' tragic fate," J. Shanxi Agric. Univ. Ssci, vol. 6, no. 9, pp. 736-739, June 2010.

[9] J. C. Yang. Ed. The New Edition of American Literature. Shanghai: Shanghai Foreign Language Education Press, 2002.

[10] C. Marcus. The Literature of the United States. Beijing: China Foreign Translation Publishing Company, 1985, p. 259.
[11] K. F. Zender, "Character and symbol in barn burning," College Literature, 1989.

[12] Y. Long, "Loyalty and rebellion-the father images in William Faulkner's A Rose for Emily and Barn Burning," J. Xiangtan Normal Univ. Ssci, vol. 28, no. 1, pp. 92-93, Jan. 2006.

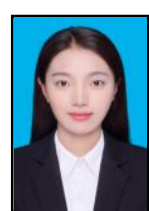

Qian Bai was born in Yulin, China, February, 1993. She received her bachelor degree of arts in English, Northwestern Polytechnical University, Xi'an, China, 2015.

She is pursuing the master degree of arts in Northwestern Polytechnical University in Xi'an, China, in British and American literature.

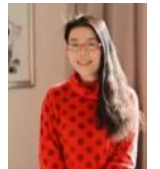

Yu Sun was born in Wuhan, China, June, 1971. Visiting Scholar, University of Maryland, America, 2014. She received her master of arts in English language and literature, Northwestern Polytechnical University, Xi'an, China, 2000.

She is the director in the Arts Education Centre of Northwestern Polytechnical University and also the Graduate Advisor on literature and translation. Prof. Sun is also a member of Translators Association of China and the reviewer of China Scholarship Council. 